\title{
How different are complications that affect the older adult inpatient?
}

\author{
D Rowell, ${ }^{1}$ H S Nghiem, ${ }^{2}$ C Jorm, ${ }^{3}$ T J Jackson ${ }^{4}$
}

\begin{abstract}
${ }^{1}$ Australian Centre for Economic Research on Health

(ACERH-UQ), The University of Queensland, Brisbane, Australia ${ }^{2}$ Centre of National Research on Disability and Rehabilitation Medicine, Herston, Australia ${ }^{3}$ The Australian Commission on Safety and Quality in Health

Care, Sydney, Australia

${ }^{4}$ School of Medicine,

ACERH-UQ, Brisbane, Australia
\end{abstract}

\section{Correspondence to}

David Rowell, Australian Centre for Economic Research on

Health, Mayne Medical School, The University of Queensland, Level 3, Herston Road, Herston 4006, Brisbane, Australia; d.rowell@uq.edu.au

Accepted 9 August 2009

\section{ABSTRACT}

Objective The incidence and cost of complications occurring in older and younger inpatients were compared.

Design Secondary analysis of hospital-recorded diagnosis and costs for multiday-stay inpatients in 68 public hospitals in two Australian states.

Main outcome measures A complication is defined as a hospital-acquired diagnosis that required additional treatment. The Australian Classification of HospitalAcquired Diagnoses system is used to identify these complications.

Results Inpatients aged $>70$ years have a $10.9 \%$ complication rate, which is not substantially different from the $10.89 \%$ complication rate found in patients aged $<70$ years. Examination of the probability by single years, however, showed that the peak incidence associated with the neonatal period and childbirth is balanced by rates of up to $20 \%$ in patients $>80$ years. Examining the adult patient population (40-70 years), we found that while some common complications are not age specific (electrolyte disorders and cardiac arrhythmias), others (urinary tract and lower respiratory tract infections) are more common in the older adult inpatient.

Conclusion For inpatients aged $>70$ years, the risks of complications increase. The incidence of hospitalacquired diagnoses in older adults differs significantly from incidence rates found in younger cohorts. Urinary tract infection and alteration to mental state are more common in older adult inpatients. Surprisingly, these complexities do not result in additional costs when compared with costs for the same complications in younger adults. Greater awareness of these differing patterns will allow patient safety efforts for older patients to focus on complications with the highest incidence and cost.

The surveillance of adverse events in inpatient treatment plays a vital role in the process of risk minimisation. While there is a rich literature examining the incidence of "adverse events", $1-3$ studies that have focused on adverse events in older adults are limited. Older adults are of concern because they are known to be at risk of an adverse event; however, estimates of incidence rates are variable. $^{4-6}$ Knowledge about adverse events that affect the treatment of older adults is also fragmentary. For example, older adults are reportedly prone to inpatient medication errors, ${ }^{7-9}$ falls ${ }^{1} 1011$ and postoperative complications. ${ }^{12}$ Yet, we could find no comprehensive overview of hospitalacquired complications (including but not limited to adverse events) that affect older adults, nor any that estimated their impact on the relative costs of care. Our aim is to report on hospital-acquired diagnoses and their relative costs in the older adult using routine data from 68 public hospitals in two Australian states.

\section{METHODS}

We conduct a secondary analysis of administrative cost data. Ordinary least squares regression is used to estimate the effect that hospital-acquired diagnoses have on the cost of an inpatient admission. In 2005-2006, separations from public hospitals located in Queensland and Victoria comprised $45.3 \%$ of the Australian total. ${ }^{13}$ Administrative data were supplied by 105 public hospitals. However, our sample of 1.69 million separations was limited to those larger public hospitals (45 hospitals in Victoria and 23 in Queensland) that were able to provide valid patient-level cost data. Thus, our analysis examined $84 \%$ of the 2.02 million public hospital separations that occurred within these two states during 2005-2006. ${ }^{13}$ Patients older than 70 years $(n=401676)$ represent $23.6 \%$ of admissions in our sample. Each de-identified record contains demographic, cost and clinical data. Clinical diagnosis is recorded using the International Statistical Classification of Diseases 10th Revision Australian Modification (ICD-10-AM) ${ }^{14}$ The data contain a principal diagnosis code with capacity for 39 additional diagnosis codes. Codes are assigned by coders using the full set of clinical notes. ${ }^{15}$

The dataset contains a condition-onset flag to indicate if the coded diagnosis was present on admission or arose during the course of the episode. ${ }^{16}$ Chronic and long-term conditions are not eligible for flagging as "hospital acquired" and were removed from further analysis using a datacleaning algorithm. ${ }^{17}$ The clinical consequences of a hospital-acquired diagnosis can result in multiple codes being assigned to a single clinical admission. We use the Australian Classification of HospitalAcquired Diagnoses (hereafter CHADx) ${ }^{18}$ to group these "not present on admission" ICD codes into 144 clinically meaningful classes, to estimate the relative incidence and costs of different types of complications in the older adult. However, an episode of care may include multiple CHADx cases. For example, $5.8 \%$ of inpatients older than 70 years recorded two or more $\mathrm{CHADx}$ and accounted for $80.8 \%$ of all recorded CHADx (see table 1 ).

Total costs are estimated using clinical costing systems that link individual utilisation of inpatient services (days of ward care, minutes in theatre, number and type of $x$ ray) by the patient's medical record number. Costs of these services are estimated from the hospital's general ledger using cost-allocation formulae (eg, salaries in theatre, diagnostic radiology 
Table 1 Frequency of hospital-acquired diagnoses in patients older than 70 years and those aged $40-70$ years

\begin{tabular}{lcllll}
\hline & \multicolumn{2}{c}{ Age $>\mathbf{7 0}$ years } & & \multicolumn{2}{c}{ Age $\mathbf{4 0}-\mathbf{7 0}$ years } \\
\cline { 2 - 3 } \cline { 6 - 6 } & Frequency & $\%$ & & Frequency & \% \\
\hline All inpatients & 401676 & 100 & 679328 & 100 \\
Inpatients with nil CHADx & 357799 & 89.1 & & 634354 & 93.4 \\
Inpatients with $\geq 1$ CHADx & 43877 & 10.9 & & 44974 & 6.6 \\
Inpatients with $>1$ CHADx & 23308 & 5.8 & & 27457 & 4.0 \\
All CHADx & 107362 & n.a. & & 95788 & n.a. \\
\hline
\end{tabular}

Source: Public hospital administrative data supplied by the Victorian and Queensland Health Departments, 2005-2006.

CHADx, Classification of Hospital-Acquired Diagnoses; n.a., not applicable.

relative value scale, etc) ${ }^{19}$ and are reported in 2006 Australian dollars (\$A).

Ordinary least squares regression is used to estimate the cost of each CHADx. We control for the underlying cost of an uncomplicated admission by using the mean cost of admissions without complication, classified by Diagnosis Related Group (DRG), and this is subtracted from the total cost of each patient with a CHADx to calculate an "adjusted cost". We include two covariates in our model: a dummy variable equal to 1 if the inpatient died in hospital (DIH), and a second dummy variable for cases treated and discharged on the same day. These were included to control for the possibility that the costs of any CHADx associated with in-hospital death would be confounded by this association, and, similarly, that same-day patients would have systematically different costs from those of multiday-stay inpatients. Using STATA $10.1{ }^{20}$ we estimated the following econometric model:

$$
\text { Adj_Cost }=\alpha_{0}+\alpha_{1} \text { CHADx }_{1 \text { to } 144}+\alpha_{2} \text { DIH }+\alpha_{3} \text { Same_day }+\varepsilon
$$

The reported "system cost" represents the regression estimate multiplied by the frequency for each $\mathrm{CHADx}$ - that is, the total cost in the two-state sample reported here.

The frequencies of all CHADx are plotted against age. The analysis is then focused on the frequencies and costs of CHADx in adults older than 70 years of age. Our results are presented in two league tables. The first lists the 20 most frequent $\mathrm{CHADx}$ and the second lists the 20 most costly CHADx that affect older adults. The league tables contrast our results in older and younger adults.

\section{RESULTS}

Figure 1 illustrates that the frequency and proportion of admissions associated with a hospital-acquired diagnosis vary with patient age. The horizontal axis plots age. The left axis measures the frequency of any hospital-acquired diagnosis, while the right axis measures the proportion of admissions associated with a hospital-acquired diagnosis.

The frequency of hospital-acquired diagnoses in newborns is high. Thereafter, the frequency drops and remains low throughout childhood. Ages 20-40 years are associated with a rise and then fall in hospital-acquired diagnosis rates, principally relating to childbirth. For example, CHADx 12.7 seconddegree perineal laceration is the most common complication in this age group (12243 cases). After the age of 40 years, the frequency of any complication increases steadily until the age of 80 years.

The proportion of admissions with a hospital-acquired diagnosis, by age, follows a similar trend, until age 80 years, when, instead of declining, it increases with each additional year of age. While nearly $20 \%$ of adults older than 80 years of age incur a hospital-acquired diagnosis, when the data are partitioned into admissions of patients $<70$ and $>70$ years, the mean for older inpatients $(10.89 \%)$ is not significantly different from that for younger inpatients (10.9\%). As higher rates of hospital-acquired diagnoses associated with childbirth had the potential to confound a comparative analysis in older adult, inpatients aged 40-70 years were selected as the appropriate comparator.

Older inpatients ( $>70$ years) who develop a hospital-acquired diagnosis have a mean cost of treatment (\$A14355) that is 5.9 times greater than inpatients that do not experience one (\$A2448). By way of contrast, inpatients aged between 40 and 70 years who develop a hospital-acquired diagnosis have a mean cost of treatment (\$A15919) that is 6.5 times larger than inpatients who do not (\$A2138).

Table 2 presents the 20 most frequently occurring individual CHADx, comparing inpatients aged $>70$ years with the
Figure 1 The frequency of any hospital acquired diagnosis in Queensland and Victoria (by age). Source: Public hospital administrative data supplied by the Victorian and Queensland Health Departments, 2005-2006. Graph was truncated at 95 years of age due to small sample sizes.

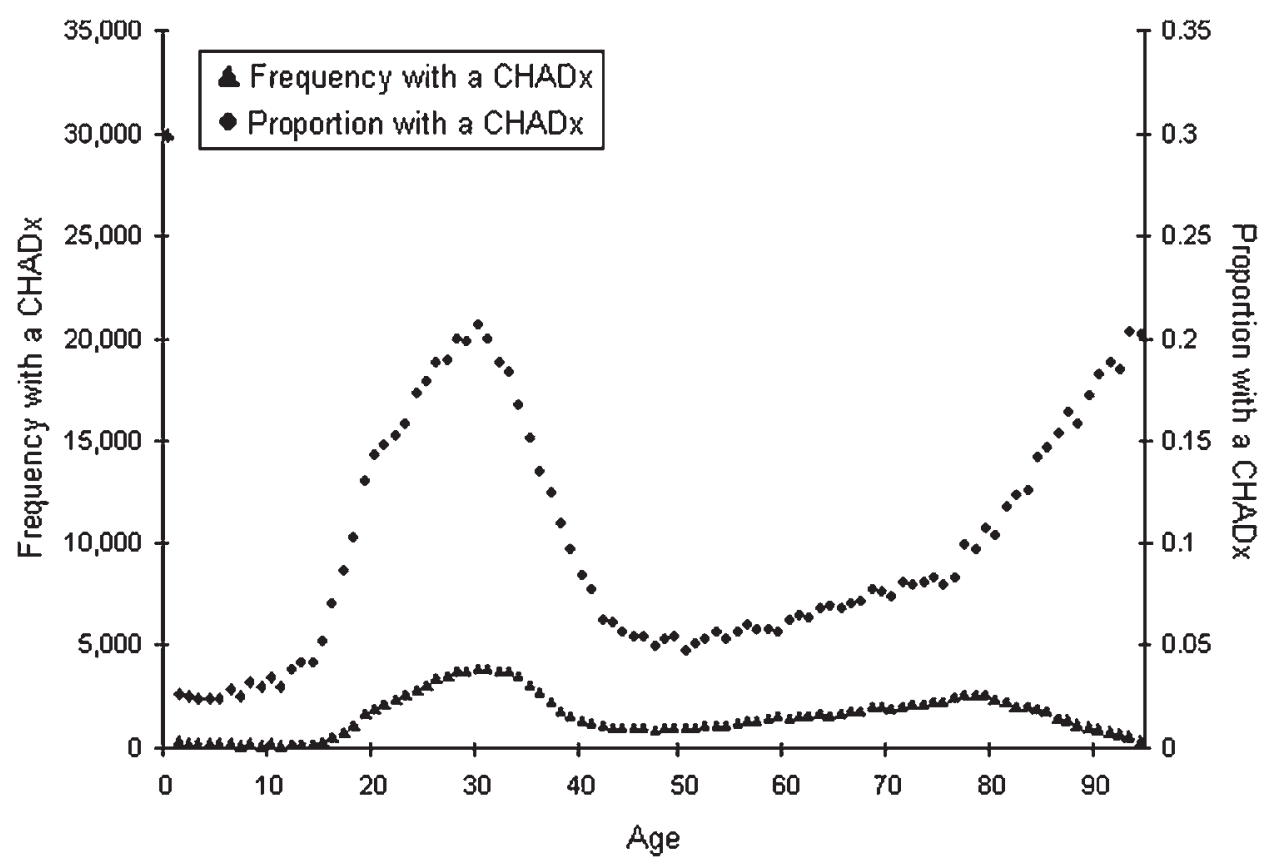


Table 2 Twenty most frequent CHADx in patients older than 70 years versus those aged $40-70$ years

\begin{tabular}{|c|c|c|c|c|c|c|c|c|c|}
\hline \multirow[b]{2}{*}{ CHADx } & \multirow[b]{2}{*}{ Description } & \multicolumn{4}{|c|}{ Age $>70$ years } & \multicolumn{4}{|c|}{ Age $40-70$ years } \\
\hline & & $\begin{array}{l}\text { Rank of } \\
\text { frequency }\end{array}$ & Frequency & $\%$ & $\begin{array}{l}\text { Total } \\
\text { cost } \$ m\end{array}$ & $\begin{array}{l}\text { Rank of } \\
\text { frequency }\end{array}$ & Frequency & $\%$ & $\begin{array}{l}\text { Total } \\
\text { cost } \$ m\end{array}$ \\
\hline 15.2 & Electrolyte disorders $w / 0$ dehydration & 1 & 8437 & 7.86 & $\$ 11.7$ & 1 & 6902 & 7.21 & $\$ 5.9$ \\
\hline 5.3 & $\begin{array}{l}\text { Cardiac arrhythmias, conduction } \\
\text { disturbances }\end{array}$ & 2 & 6899 & 6.43 & $\$ 9.1$ & 2 & 5196 & 5.42 & $\$ 5.9$ \\
\hline 5.6 & Hypotension (not drug induced) & 3 & 5201 & 4.84 & $\$ 6.1$ & 3 & 4343 & 4.53 & $\$ 3.6$ \\
\hline 9.2 & UTIs & 4 & 4313 & 4.02 & $\$ 10.2$ & 11 & 1917 & 2 & $\$ 10.3$ \\
\hline 10.4 & Alterations to mental state & 5 & 3526 & 3.28 & $\$ 5.0$ & 17 & 1604 & 1.67 & $\$ 7.6$ \\
\hline 7.4 & Constipation & 6 & 2916 & 2.72 & $\$ 7.1$ & 9 & 2040 & 2.13 & $\$ 9.1$ \\
\hline 6.3 & $\begin{array}{l}\text { Acute lower respiratory infections } \\
\text { (including influenza and pneumonia) }\end{array}$ & 7 & 2719 & 2.53 & $\$ 11.1$ & 13 & 1781 & 1.86 & $\$ 11.1$ \\
\hline 9.4 & $\begin{array}{l}\text { Other complications and symptoms of the } \\
\text { urinary system }\end{array}$ & 8 & 2582 & 2.4 & $\$ 2.9$ & 16 & 1630 & 1.7 & $\$ 1.5$ \\
\hline 14.2 & Other hospital-acquired anaemia & 9 & 2402 & 2.24 & $\$ 5.0$ & 8 & 2077 & 2.17 & $\$ 7.0$ \\
\hline 15.1 & Dehydration/volume depletion & 10 & 2390 & 2.23 & $\$ 1.9$ & 19 & 1467 & 1.53 & $\$ 0.7$ \\
\hline 9.1 & $\begin{array}{l}\text { Acute and unspecified renal failure } \\
\text { (excluding postprocedural) }\end{array}$ & 11 & 2246 & 2.09 & $\$ 5.3$ & 27 & 1186 & 1.24 & $\$ 5.8$ \\
\hline 8.3 & Dermatitis, rash and other skin effects & 12 & 2199 & 2.05 & $\$ 5.9$ & 10 & 1967 & 2.05 & $\$ 6.9$ \\
\hline 6.1 & $\begin{array}{l}\text { ARDS, respiratory failure and pulmonary } \\
\text { collapse (including atelectasis) }\end{array}$ & 13 & 2151 & 2 & $\$ 6.5$ & 7 & 2220 & 2.32 & $\$ 5.7$ \\
\hline 9.3 & Urinary retention & 14 & 2057 & 1.92 & $\$ 0.7$ & 24 & 1345 & 1.4 & $\$ 0.7$ \\
\hline 7.1 & Gastroenteritis & 15 & 2037 & 1.9 & $\$ 7.7$ & 12 & 1826 & 1.91 & $\$ 9.6$ \\
\hline 5.5 & Heart failure & 16 & 2001 & 1.86 & $\$ 0.0$ & 37 & 795 & 0.83 & $\$ 2.4$ \\
\hline 1.4 & $\begin{array}{l}\text { Postprocedural haemorrhage and } \\
\text { haematoma }\end{array}$ & 17 & 1899 & 1.77 & $\$ 4.8$ & 5 & 2432 & 2.54 & $\$ 7.4$ \\
\hline 7.5 & Nausea and vomiting & 18 & 1895 & 1.77 & $\$ 1.6$ & 4 & 3141 & 3.28 & $\$ 0.0$ \\
\hline 8.1 & Pressure ulcers & 19 & 1834 & 1.71 & $\$ 8.8$ & 35 & 809 & 0.84 & $\$ 12.8$ \\
\hline 5.1 & AMI & 20 & 1717 & 1.6 & $\$ 2.5$ & 57 & 470 & 0.49 & $\$ 0.9$ \\
\hline
\end{tabular}

Source: Public hospital administrative data supplied by Victorian and Queensland Health Departments, 2005-2006.

AMI, acute myocardial infarction; ARDS, acute respiratory distress syndrome; CHADx, Classification of Hospital-Acquired Diagnoses; UTI, urinary tract infection.

corresponding frequency and cost of the same complication in inpatients aged $40-70$ years.

The top three complications have the same ranks in the two age groups, indicating that these are commonly occurring hospital-acquired diagnoses, regardless of patient age. However, below this, a distinctive pattern arises for older adult inpatients, with CHADx 9.2 (urinary tract infections) ranking 4th for the older adult, but 11th for younger adults, and CHADx 10.4 (alterations to mental state) ranking 5th among the older adult, in contrast to a ranking of 17 th among the younger inpatient population. Older patients have more than twice the rate of pressure ulcers (CHADx 8.1) and three times the rate of hospital-acquired acute myocardial infarction (CHADx 5.1).

Table 3 shows the partial regression coefficients for control variables, while table 4 lists the regression-estimated cost of the 20 highest-cost CHADx in the older adult (with the corresponding cost ranks in younger adult patients (40-70 years)). The signs on these coefficients are as expected. Dying in hospital is cost-saving. Same-day inpatients are less costly than multiday patients are. The model included dummy variables for 144 CHADx classes, of which 28 were dropped because they were

Table 3 Regression results

\begin{tabular}{lrlrl}
\hline $\begin{array}{l}\text { Dependent variable; } \\
\text { adjusted cost }\end{array}$ & Coefficient & SE & t score & p Value \\
\hline Intercept & 4.05 & 11.70 & 0.35 & 0.729 \\
Same-day inpatient & -41.64 & 13.94 & -2.99 & $<0.01$ \\
Died in hospital & -1012.74 & 41.05 & -24.67 & $<0.01$ \\
$\mathrm{R}^{2}$ & 0.26 & & & \\
\hline
\end{tabular}

Source: Public hospital administrative data supplied by Victorian and Queensland Health Departments, 2005-2006.

The coefficients for the 144 CHADx classes are not shown in table 3. not clinically relevant to the older adult (eg, prenatal injuries (CHADx 13.1)).

The dependent variable in this analysis is the net cost per patient once the mean cost of uncomplicated admissions in the relevant DRG class has been removed. Thus, the net effect of a CHADx on cost is given by adding the intercept term to the $\mathrm{CHADx}$ coefficient. In total, 105 of the 116 remaining $\mathrm{CHADx}$ codes increase the cost of an admission, of which 99 were statistically significant at the $95 \%$ level of confidence.

Our econometric model also produces seven negative coefficients that are statistically significant. These CHADx are associated with anaesthesia. It is not clear why these hospitalacquired diagnoses would reduce the cost of an admission. Perhaps the data contain insufficient detail to control for patient acuity; alternatively, CHADx may truly be cost reducing. For example, anaesthetic complications could lead to cancellation of surgery. Although unexpected, the absolute size of these negative coefficients is not large and does not detract from our ability to interpret findings.

Table 4 illustrates the fact that total system cost reflects an interaction between the number of cases and the additional cost for each case. In older inpatients, although CHADx 15.2 (electrolyte disorder (without dehydration)) is less costly per patient than other CHADx, the frequency of this complication makes it more costly to the system. By way of contrast, electrolyte disorder (without dehydration) is the 21st most costly complication among adults aged 40-70 years. Conversely, the highestimpact complication in the younger group (septicaemia (CHADx 4.1)) adds $\$ A 7689$ per older patient episode, but with fewer cases, ranks only 5 th for this group.

A divergence is apparent between the younger cohort and patients $>70$ years in patterns of complication costs. Hypotension (CHADx 5.6) and falls (excluding those with fractured neck 
Table 4 Twenty most costly complications in patients older than 70 years versus those aged $40-70$ years

\begin{tabular}{|c|c|c|c|c|c|c|}
\hline CHADx & Description & Coefficient & Frequency & Cost \$m & $\begin{array}{l}\text { Rank cost } \\
\text { (>70 years) }\end{array}$ & $\begin{array}{l}\text { Rank cost } \\
\text { (40-70 years) }\end{array}$ \\
\hline 15.2 & Electrolyte disorders w/o dehydration & 1386.2 & 8437 & $\$ 11.7$ & 1 & 21 \\
\hline 6.3 & $\begin{array}{l}\text { Acute lower respiratory infections } \\
\text { (including influenza and pneumonia) }\end{array}$ & 4096.8 & 2719 & $\$ 11.1$ & 2 & 4 \\
\hline 9.2 & UTIs & 2364.1 & 4313 & $\$ 10.2$ & 3 & 5 \\
\hline 5.3 & $\begin{array}{l}\text { Cardiac arrhythmias, conduction } \\
\text { disturbances }\end{array}$ & 1324.3 & 6899 & $\$ 9.1$ & 4 & 20 \\
\hline 4.1 & Septicaemia & 7689.3 & 1154 & $\$ 8.9$ & 5 & 1 \\
\hline 8.1 & Pressure ulcers & 4820.9 & 1834 & $\$ 8.8$ & 6 & 2 \\
\hline 7.1 & Gastroenteritis & 3766.0 & 2037 & $\$ 7.7$ & 7 & 6 \\
\hline 7.4 & Constipation & 2434.6 & 2916 & $\$ 7.1$ & 8 & 8 \\
\hline 7.7 & Other digestive system disorders & 6207.2 & 1131 & $\$ 7.0$ & 9 & 7 \\
\hline 1.10 & $\begin{array}{l}\text { Complications of cardiac and vascular } \\
\text { implants (excluding septicaemia) }\end{array}$ & 5733.1 & 1216 & $\$ 7.0$ & 10 & 3 \\
\hline 6.1 & $\begin{array}{l}\text { ARDS, respiratory failure and pulmonary } \\
\text { collapse (including atelectasis) }\end{array}$ & 3042.6 & 2151 & $\$ 6.5$ & 11 & 18 \\
\hline 5.6 & Hypotension (not drug induced) & 1164.3 & 5201 & $\$ 6.1$ & 12 & 39 \\
\hline 8.3 & Dermatitis, rash and other skin effects & 2670.6 & 2199 & $\$ 5.9$ & 13 & 13 \\
\hline 6.4 & $\begin{array}{l}\text { Pulmonary oedema, pneumothorax and } \\
\text { pleural effusion }\end{array}$ & 4298.0 & 1342 & $\$ 5.8$ & 14 & 9 \\
\hline 3.3 & All other falls & 3700.9 & 1519 & $\$ 5.7$ & 15 & 36 \\
\hline 9.1 & $\begin{array}{l}\text { Acute and unspecified renal failure } \\
\text { (excluding postprocedural) }\end{array}$ & 2370.6 & 2246 & $\$ 5.4$ & 16 & 17 \\
\hline 14.2 & Other hospital-acquired anaemia & 2087.4 & 2402 & $\$ 5.0$ & 17 & 12 \\
\hline 10.4 & Alterations to mental state & 1411.3 & 3526 & $\$ 5.0$ & 18 & 10 \\
\hline 4.2 & Mycoses & 4410.7 & 1117 & $\$ 4.9$ & 19 & 15 \\
\hline 1.9 & Wound infection (excluding septicaemia) & 6643.7 & 726 & $\$ 4.8$ & 20 & 19 \\
\hline
\end{tabular}

Source: Public hospital administrative data supplied by the Victorian and Queensland Health Departments, 2005-2006.

ARDS, acute respiratory distress syndrome; CHADx, Classification of Hospital-Acquired Diagnoses; UTI, urinary tract infection.

of femur or with intracranial injury) (CHADx 3.3) would not even appear in the top 20 total system cost for younger adults (ranks 39 and 36, respectively). In general, the largest system cost-impact complications in the older adult are more common ones such as urinary tract infections, pneumonias and cardiac arrhythmias, with lower per-case costs.

\section{DISCUSSION}

Improving outcomes for older adult inpatients is going to require taking a broader view than the current literature allows. Previous studies have focused on individual sources of harm to older adult inpatients but did not place these in the context of all hospital-acquired illness and injury. Priority setting for patient safety programmes needs to take into account the frequency and the total system cost of hospital-acquired diagnoses.

The aggregation of inpatient complications by clinical type provides a global perspective of the burden of hospital-acquired disease. Cardiovascular complications are most frequent in adults over 70 years (4.8\%), with metabolic and genitourinary complications occurring in $3.5 \%$ and $2.9 \%$ of inpatients aged over 70 years, respectively. Although only sixth ranked by volume, postprocedural complications are the most costly in the sample, representing $15.4 \%$ of excess costs attributable to complications in the older adult. Analysis of the $144 \mathrm{CHADx}$ classes provides specific details about relative frequency and costs. We demonstrate that the hospital-acquired diagnoses that affect older adults are qualitatively distinct. Older adults are particularly prone to urinary tract infections (CHADx 9.2), alterations to mental state $(\mathrm{CHADx} 10.4)$ and lower respiratory tract infections (CHADx 6.3).

By using multivariate regression to analyse costs, we are able to distinguish those costs that are attributable to the patient's primary diagnosis from those that can be attributed to other causes, including hospital-acquired conditions. In older adult inpatients, CHADx 15.2 (electrolyte disorders (without dehydration)) are more costly to the system than CHADx 4.1 (septicaemia).

Our aim was to utilise routine hospital data to describe the epidemiology of a broader range of complications that affect the older adult inpatient. Bates et al said:

"[t]he "holy grail" in computerized adverse event detection has been a tool to detect a large fraction of all adverse events... Such a tool could be used by hospitals for routine detection of adverse events on an ongoing basis and in real time." ${ }^{21}$

The condition-onset marker enabled the CHADx coding algorithm to distinguish pathophysiology, which was present on admission from conditions, which developed subsequently. Quite obviously, it is not possible to prevent all hospitalacquired illness and injury. Nevertheless, identified adverse events may miss a range of preventable complications of care, which jeopardise patient recovery and add to healthcare system costs.

Our data, which were obtained from 68 public hospitals and comprise $84 \%$ of all public separations, could bias cost estimates if the selected hospitals implement clinical protocols that were systematically different from non-selected hospitals. However, hospital audits by the Australian Council on Healthcare Standards $^{22}$ and the registration of various healthcare professionals by state medical and nursing boards are designed to ensure a consistent, minimum standard of patient treatment.

Our findings, however, are clearly dependent on the quality of coding and prefixing of diagnoses in hospitals. Although we consider the quality assurance programs in the two public hospital systems to be robust, we have not verified coding quality. We are not able to attribute causation or preventability with the data reported here; however, we consider that judicious 
analysis of administrative data offers a cost-effective method to evaluate interventions designed to reduce complications of inpatient care. CHADx may be useful as a screening tool to estimate rates and patterns of untoward in-hospital outcomes in the older adult and other inpatient subpopulations of interest.

Economic priorities for patient safety programmes should obviously factor in the expected benefits for patient survival and quality of life of preventing particular kinds of complications. A better understanding of the financial burden of these complications can help make the "business case" for greater investment in evidence-based patient safety programmes and in further research on how best to prevent inpatient harms.

Funding The Australian Commission on Safety and Quality in Health Care, GPO Box 5480 Sydney, New South Wales, Australia, 2001.

Competing interests None.

Provenance and peer review Not commissioned; externally peer reviewed.

\section{REFERENCES}

1. Brennan TA, Leape LL, Laird NM, et al. Incidence of adverse events and negligence in hospitalized patients. results of the Harvard Medical Practice Study I. N Engl J Med 1991;324:370-6.

2. Wilson RM, Runciman WB, Gibberd RW, et al. The quality in Australian health care study. Med J Aust 1995:163:458-71.

3. Thomas EJ, Studdert DM, Runciman WB, et al. A comparison of iatrogenic injury studies in Australia and the USA I: context, methods, case mix, population, patient and hospital characteristics. Int J Oual Health Care 2000:12:371-8.

4. Thomas EJ, Brennan TA. Incidence and types of preventable adverse events in elderly patients: population based review of medical records. BMJ 2000;320: 741-4.

5. Sari ABA, Cracknell A, Sheldon TA. Incidence, preventability and consequences of adverse events in older people: results of a retrospective case-note review. Age Ageing 2008;37:265-9.

6. Bellomo R, Goldsmith D, Russell S, et al. Postoperative serious adverse events in a teaching hospital: a prospective study. Med J Aust 2002;176:216-18.
7. Gray SL, Sager M, Lestico MR, et al. Adverse drug events in hospitalized elderly. J Gerontol A Biol Sci Med Sci 1998;53:59-63.

8. Azad N, Tierney M, Victor G, et al. Adverse drug events in the elderly population admitted to a tertiary care hospital/practitioner application. J Healthc Manag 2002; 47:295

9. Leape LL, Brennan TA, Laird N, et al. The nature of adverse events in hospitalized patients. results of the Harvard Medical Practice Study II. N Engl J Med 1991;324:377-84.

10. Cumming RG, Sherrington C, Lord SR, et al. Cluster randomised trial of a targeted multifactorial intervention to prevent falls among older people in hospital. BMJ 2005;336:758-60.

11. Thomas EJ, Studdert DM, Burstin HR, et al. Incidence and types of adverse events and negligent care in Utah and Colorado. Med Care 2000;38:261-71.

12. Jin F, Chung F. Minimizing perioperative adverse events in the elderly. Br J Anaesth 2001:87:608-24.

13. Australian Institute of Health and Welfare. Australian hospital statistics 2005-06. Canberra: Australian Institute of Health and Welfare, 2007.

14. NCCH (National Centre for Classification in Health). The international statistical classification of diseases and related health problems, tenth revision, Australian modification (ICD-10-AM), Vols 1-5. Sydney: National Centre for Classification in Health, 2006.

15. VDHS (Victorian Department of Human Services). Bulletin of the Health Data Standards and Systems Division. 2008. (accessed 5 Sep 2008). http://www.health. vic.gov.au/hdss/bulletin/126-110108.pdf.

16. VDHS (Victorian Department of Human Services Health Data Standards and Systems Unit). Victorian Additions to the Australian Coding Standards: Prefixes for diagnoses. 2005. (accessed 3 Mar 2008). http://www.health.vic.gov.au/hdss/ icdcoding/vicadditions/vicadd05.pdf.

17. Jackson TJ, Michel JL, Roberts R, et al. Development of a validation algorithm for 'condition onset' flagging of ICD-10-AM coded data. BMC Med Inform Decis Mak 2009;9:48.

18. Jackson TJ, Michel JL, Roberts R, et al. A classification of hospital acquired diagnoses for use with routine hospital data. Med J Aust 2009;191:544-8.

19. Jackson T. Cost estimates for hospital inpatient care in Australia: evaluation of alternative sources. Aust N Z J Public Health 2000;24:234-41.

20. StataCorp. Statistical Software Release 10.1 SE. College Station (TX): Stata Corporation, 2007.

21. Bates DW, Evans RS, Murff $\mathrm{H}$, et al. Detecting adverse events using information technology. J Am Med Inform Assoc 2003;10:115-28.

22. ACHS. Australian Council on Healthcare Standards (ACHS) - what we do, 2009 Sydney: (accessed 13 Jul 2009). http://www.achs.org.au/whatwedo/. 


\section{How different are complications that affect the older adult inpatient?}

D Rowell, H S Nghiem, C Jorm, et al.

Qual Saf Health Care 2010 19: e34

doi: 10.1136/qshc.2009.032235

\begin{tabular}{|c|c|}
\hline & $\begin{array}{l}\text { Updated information and services can be found at: } \\
\text { http://qualitysafety.bmj.com/content/19/6/e34.full.html }\end{array}$ \\
\hline & These include: \\
\hline References & $\begin{array}{l}\text { This article cites } 16 \text { articles, } 5 \text { of which can be accessed free at: } \\
\text { http://qualitysafety.bmj.com/content/19/6/e34.full.html\#ref-list-1 }\end{array}$ \\
\hline $\begin{array}{l}\text { Email alerting } \\
\text { service }\end{array}$ & $\begin{array}{l}\text { Receive free email alerts when new articles cite this article. Sign up in } \\
\text { the box at the top right corner of the online article. }\end{array}$ \\
\hline
\end{tabular}

Notes

To request permissions go to:

http://group.bmj.com/group/rights-licensing/permissions

To order reprints go to:

http://journals.bmj.com/cgi/reprintform

To subscribe to BMJ go to:

http://group.bmj.com/subscribel 